\title{
Characterization of Surface Heat Fluxes over Heterogeneous Areas Using Landsat 8 Data for Urban Planning Studies
}

\author{
Tatygul URMAMBETOVA 1 \\ ${ }^{1}$ Kyrgyz State University of Construction, Transport and Architecture, Bishkek, KYRGYZSTAN \\ E-mail: tatygul_urmambetova@yahoo.com \\ DOI: 10.24193/JSSP.2017.1.04
}

https://doi.org/10.24193/JSSP.2017.1.04

K e y w o r d s: land surface temperature, land use/land cover, NDVI, sensible heat flux

\begin{abstract}
A B S T R A C T
Land surface temperature (LST) is a key indicator of the Earth's surface energy and it is one of the important inputs in hydrological, meteorological and climatological applications. It is also important for global change studies and acts as a controlling variable in climatic models. Estimation of LST from satellite thermal infrared radiometer has proven to be very useful. The present work employs temporal Landsat 8 data over Delhi region to characterize the land surface (urban and non-urban) using thermal intensity and sensible heat flux. A full-scene of the Landsat 8 acquired on April 11 and October 20, 2013 (path/146- row/40) of Delhi area and surroundings was used in this study. In pre-processing atmospheric correction was carried out using image based and model based techniques. The pre-processed data was used for land use land cover (LULC) classification by supervised classification method. In the study area, six classes were considered, as follows: Water body; Forest; Agriculture/Park; Bare soil; High density built-up and Low density built-up. The Landsat 8 near infrared and red bands were used to estimate the vegetation index, surface emissivity whereas the thermal bands were employed to calculate land surface temperature using the generalized split window algorithm. In order to have information on heat fluxes over different land surfaces, sensible heat flux was evaluated and stratified over urban and non-urban features. The study reveals that the methodology proves to be suitable to effectively characterize the heterogeneous land surface.
\end{abstract}

\section{INTRODUCTION}

Remotely sensing imagery has been used for developing and validating various studies regarding land cover dynamics such as normalized difference vegetation index (NDVI), emissivity, land surface temperature (LST) and etc. [1], [2]. The climate in and around cities and other built up areas is altered due to changes in land use land cover (LULC) and anthropogenic activities of urbanization. The most imperative problem in urban areas is the increasing surface temperature due to alteration and conversion of vegetated surfaces to impervious surfaces. These changes affect the absorption of solar radiation, surface temperature, evaporation rates, storage of heat, wind turbulence and can drastically alter the conditions of the near-surface atmosphere over the cities. The temperature difference between urban and rural settings is usually called urban heat island (UHI) [3], [4], [5]. The UHI effects are exacerbated by the anthropogenic heat generated by traffic, industry and domestic buildings, impacting the local climate through the city's compact mass of buildings that affect exchange of energy and levels of conductivity. The higher temperatures in urban heat islands increase air conditioning demands, raise pollution levels, and may modify precipitation patterns [6].

Delhi is one of the many megacities where urbanization is taking place at a faster race [7]. Urban growth and sprawl have severely altered the biophysical environment. Unplanned urbanization an urban sprawl will directly affect the land use and land cover of the 
area. The changes in land use/cover include loss of agricultural lands, loss of forest lands, increase of barren area, increase of impermeable surface of the area because of the built up area etc. [4].

\section{THEORY AND METHODOLOGY}

To fulfil the following objectives, such as, evaluation the performance of atmospheric correction on derived parameters (NDVI, Emissivity, LST); estimation of land surface temperature, sensible heat flux (SHF) and other relative parameters; evaluate the parameters derived and study their relationship in urban and vegetated areas research work was done by below given Methodological flowchart (Fig. 1).

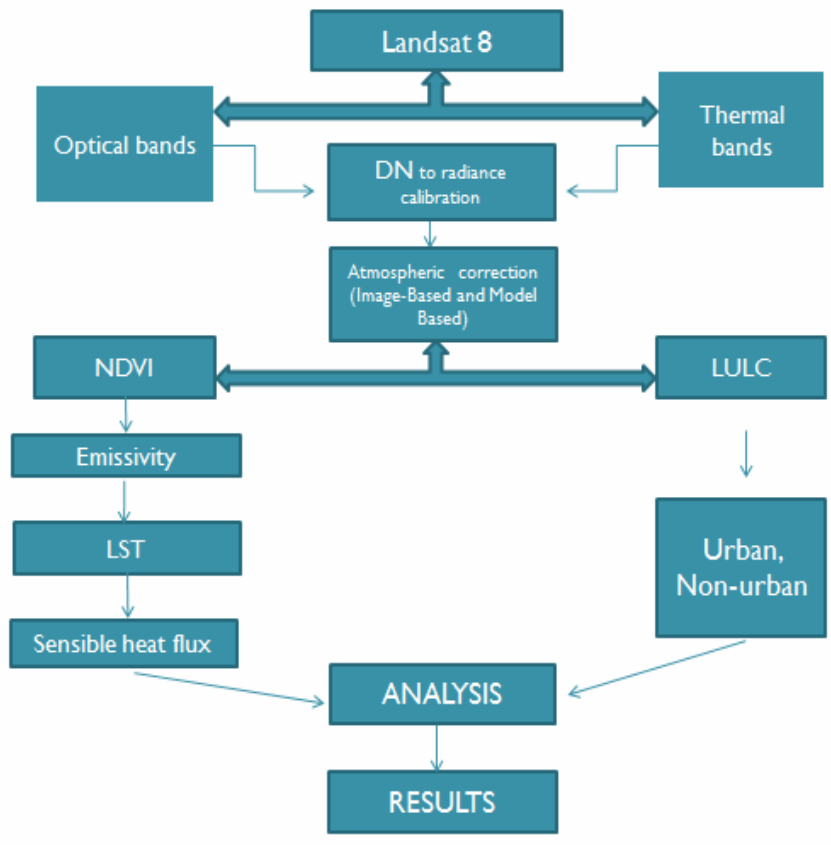

Fig. 1. Methodological flow chart.

\subsection{Atmospheric correction}

The optical remote sensing data not only contain the signal reflected from the Earth surface, but also contain diffusing and reflecting signals. The radiance measured by the sensor may be affected depending on the prevailing atmospheric conditions at the time of satellite image acquisition. Hence it is essential to consider the atmospheric effects and to apply the necessary atmospheric corrections. Atmospheric correction was done using two techniques, Image-Based (DOS - dark object subtraction) [8] and Model-Based (FLAASH - Fast Line-of-sight Atmospheric Analysis of Spectral Hypercubes), using the software ENVI 5.1. The input image for FLAASH must be a radio-metrically calibrated radiance image in band interleaved by line (BIL) or band interleaved by pixel (BIP) format. The data type may be floating-point, 4-byte signed integers, 2-byte signed integers, or 2-byte 50 unsigned integers. Input parameters which were used in FLAASH model are given in Table 1.

Table 1. Input parameters for atmospheric correction using FLAASH.

\begin{tabular}{l|r}
\multicolumn{1}{c|}{ Input parameters } & \multicolumn{1}{|c}{ Value/ description } \\
\hline Single scale factor & 10.000000 \\
Sensor type & Landsat 8 \\
Sensor Altitude (km) & 705 \\
Scene centre location & Lat: 28,86924, Lon:77.91354 \\
Ground Elevation (km) & 0.219 \\
Flight date & April -11-2013--- (October- \\
Flight time (HH:MM:SS) & $20-2013)$ \\
Atmosphere type & 05:22:30---(05:20:40) \\
Aerosol model & Tropical \\
Aerosol retrieval & Urban \\
& None
\end{tabular}

\subsection{Derivation of NDVI values}

The NDVI is one of the most widely used index of which applicability in satellite analysis and in monitoring of vegetation cover was sufficiently verified in the last two decades [9]. It gives a measure of the vegetative cover on the land surface over wide areas. Dense vegetation shows up very strongly in the imagery and areas with little or no vegetation are also clearly identified. NDVI also identifies water and ice. Vegetation differs from other land surfaces because it tends to absorb strongly the red wavelengths of Sun light and reflect in the near-infrared wavelengths. Landsat satellites measure the intensity of the reflection from the Earth's surface in both these wavelength ranges. The NDVI is a measure of the difference in reflectance between these wavelength ranges. NDVI takes values between -1 and 1 , values of 0.5 indicating dense vegetation and values $<0$ indicating no vegetation. NDVI values for the vegetation cannot be lower than 0 . The index is defined by equation 1 .

$$
N D V I=\frac{(N I R-R E D)}{N I R+R E D}
$$

\subsection{Estimation of LST, SHF}

All objects at temperatures above absolute zero emit thermal radiation. However, for any particular wavelength and temperature the amount of thermal radiation emitted depends on the emissivity of the object's surface. The emissivity of a surface is controlled by suchfactors as water content, chemical composition, structure and roughness. For vegetated surfaces 
emissivity can vary significantly with plant species, areal density, and growth stage [5]. Emissivity is defined as the ratio between the actual radiance emitted by a real world selective radiating body and a blackbody at the same thermodynamic (kinetic) temperature [10]. It is a dimensionless number between o (for a perfect reflector) and 1 (for a perfect emitter). Knowledge of surface emissivity is important both for accurate noncontact temperature measurement and for heat transfer calculations. Radiation thermometers detect the thermal radiation emitted by a surface. They are generally calibrated using blackbody reference sources that have an emissivity as close to 1 as makes no practical difference. The emissivity of a material surface depends on many chemical and physical properties it is often difficult to estimate. It must either be measured or modified in some way, for example by coating the surface with high emissivity black paint, to provide a known emissivity value [11].

There were done several researches for estimation LST values using the Generalized Split Window algorithm [12], [13], [14]. Numerous factors need to be quantified in order to assess the accuracy of the LST retrieval from satellite data, including sensor radiometric calibrations [15], atmospheric correction, surface emissivity correction, characterization of spatial variability in land cover, and the combined effects of viewing geometry, background, and fractional vegetative cover. In the estimation of LST from satellite thermal data, the digital number (DN) of image pixels needs to be converted into spectral radiance using the sensor calibration data. However, the radiance converted from digital number does not represent a true surface temperature but a mixed signal or the sum of different fractions of energy. These fractions include the energy emitted from the ground, upwelling radiance from the atmosphere, as well as the downwelling radiance from the sky integrated over the hemisphere above the surface. Therefore, the effects of both surface emissivity and atmosphere must be corrected in the accurate estimation of LST.

LSE (land surface emissivity) can be extracted by using NDVI considering three different cases (1) bare ground (2) fully vegetated and (3) mixture of bare soil and vegetation [16].

Before obtaining the LST values the digital number (DN) values were converted into a spectral radiance [6], then calculated the at-satellite brightness temperature by using the following equation [3], [4]:

$$
T=\frac{K_{2}}{\ln \left(\frac{K_{1}}{L_{\lambda}}+1\right)}
$$

where:

$\mathrm{T}-$ at satellite brightness temperature (Kelvin);
$\mathrm{L}_{\lambda} \quad$ - top-of-atmosphere (TOA) spectral radiance;

$\mathrm{K}_{1}-$ Band-specific thermal conversion constant;

$\mathrm{K}_{2}$ - Band-specific thermal conversion constant (from the metadata). The values for Landsat 8 were as follows, band 10: K1 = 774.89, K2 = 1321.08; band 11: $\mathrm{K} 1=480.89, \mathrm{~K} 2=1201.14$.

Since the 1970s, remote sensing technology has brought the hope of estimating areal sensible and latent heat flux over heterogeneous surface. The development of high resolution, multi-bands, multitemporal and multiangular remote sensing data has made it possible to obtain geometric structure, water and heat conditions of surface comprehensively. For remote sensing method, sensible heat flux is estimated following Ohm's Law, using the difference between surface temperature retrieved from remote sensing data and air temperature. Then latent heat flux can be calculated according to surface energy balance equation expressed as:

$$
L E=R_{n}-G-\rho C_{p} \frac{T_{s}-T_{a}}{r_{a h}}
$$

where: LE is latent heat flux; $\mathrm{R}_{\mathrm{n}}$ is net radiation; $G$ is soil heat flux; $\rho$ is air density; $C_{p}$ is the specific heat of air at constant pressure; Ts, Ta are surface temperature and air temperature respectively; $r_{a h}$ is the aerodynamic resistance to heat transfer [17].

\section{RESULTS AND DISCUSSION}

\subsection{General characteristics of the study area}

New Delhi (Fig. 1) and its surrounding areas were considered as study area for this research work. Delhi also known as the National Capital Territory (NCT) of India is a metropolitan region in India. With a population of 22 million in 2011, it is the world's second and the largest city in India in terms of area. The National Capital Territory of Delhi covers an area of $1,484 \mathrm{~km}^{2}$, of which $783 \mathrm{~km}^{2}$ is designated rural and $700 \mathrm{~km}^{2}$ urban therefore making it the largest city in terms of area in the country. It has a length of $51.9 \mathrm{~km}$ and a width of $48.48 \mathrm{~km}$.

The climate of Delhi is a monsoon-influenced humid subtropical (Köppen climate classification) with high variation between summer and winter temperatures and precipitation. Summer starts in early April and peak in May, with average temperatures near $32^{\circ} \mathrm{C}$, although occasional heat waves can result in highs close to $45^{\circ} \mathrm{C}$ on some days. The monsoon starts in late June and lasts until mid-September, with about $797.3 \mathrm{~mm}$ of rain. The average temperatures are around $29^{\circ} \mathrm{C}$, although they can vary from around $25^{\circ} \mathrm{C}$ on rainy days to $32^{\circ} \mathrm{C}$ during dry spells. The monsoons 
recede in late September, and the post-monsoon season continues till late October, with average temperatures sliding from $29^{\circ} \mathrm{C}$ to $21^{\circ} \mathrm{C}$.

\subsubsection{Data used}

Landsat 8 is an American Earth observation satellite launched on February 11, 2013. It is the eighth satellite in the Landsat program; the seventh reached the orbit successfully. Originally called the Landsat Data Continuity Mission (LDCM), it is collaboration between NASA and the United States Geological Survey (USGS). Details of the used data are given below in the Table 2.

The ancillary meteorological data from the websites: http://www.mosdac.gov.in, www.wunder ground.com was used.

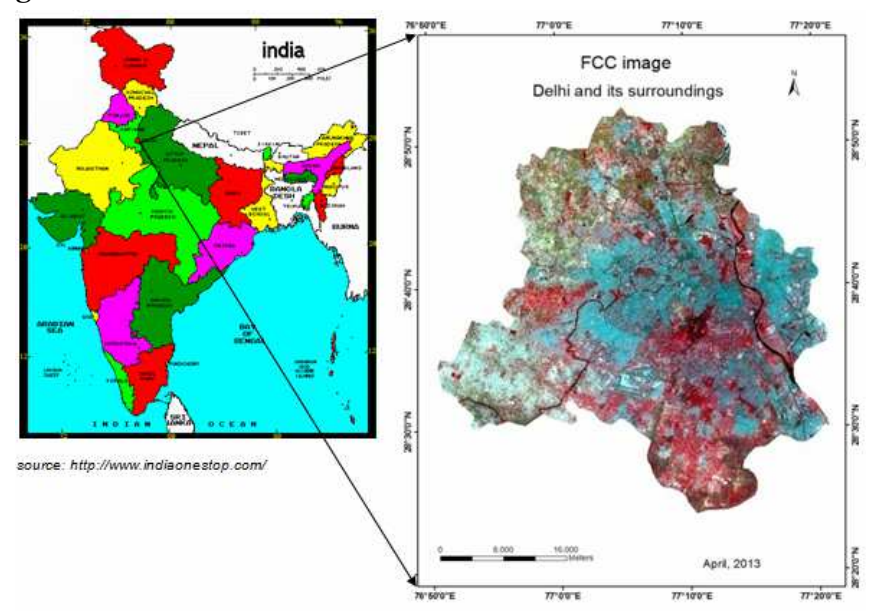

Fig. 2. Location of the study area.

Table 2. Details of the Landsat 8.

\begin{tabular}{l|rr}
\multicolumn{1}{c|}{ Month } & \multicolumn{1}{c}{ April } & \multicolumn{1}{c}{ October } \\
\hline Satellite & Landsat 8 & Landsat 8 \\
Sensor & OLI and TIRS & OLI and TIRS \\
Acquisition date & $2013 / 04 / 11$ & $2013 / 10 / 20$ \\
Path & 146 & 146 \\
Row & 40 & 40 \\
Acquisition time & $05: 22: 30$ & $05: 20: 40$ \\
Cloud cover & 1.83 & 2.56
\end{tabular}

\subsection{Analysis of land use/ land cover}

All data were analyzed using various tools of ERDAS Imagine, ENVI and ArcMap software. Spatial analyses were done throughout creating maps and studying relationships of derived parameters. Figure 3 shows the classified image. From images it is clearly visible that residential areas (high dense built-up and low dense built-up) in the central and eastern part. Agricultural are mostly in the north and north-eastern 52 part, parks and playgrounds are found in central and southern part of Delhi. Small water bodies are seen towards north area. Thin canals are also seen flowing from north-east tosouth-west. River Yamuna flows from north-east to south-east of the image.

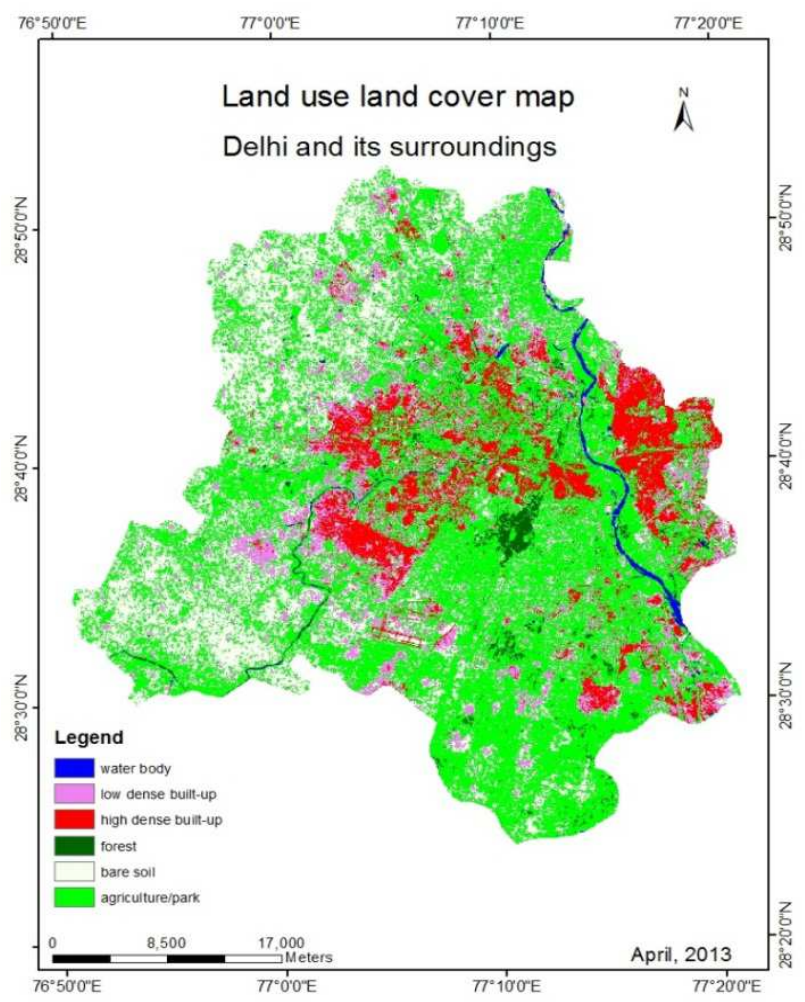

Fig. 3. Land use/land cover map.

\subsection{Analysis of normalized difference vegetation index}

NDVI values for April 11, 2013 data before atmospheric correction were in range -0.126 to 0.416 , after applying the Scene -Based Empirical Approaches (Dark object subtraction) technique NDVI values were in range (-0.163 to 0.594) and after FLAASH values have been improved and were in range (-0.244 to 0.658). For October 20, 2013 values observed between -0.097 to 0.453 before atmospheric correction after applying the Scene - Based Empirical Approach (Dark object subtraction) technique NDVI values were in range (-0.223 to 0.681) and after using Physical Model based correction (FLAASH) values have been improved and were in range (-0.312 to 0.749). Figure 4 depicts the NDVI image before and after atmospheric correction (DOS). The images show that the overall range of NDVI has been improved.

Figure 5 depicts the emissivity values for LULC classes. For example, water body values are between (0.97 - 0.99), vegetation (0.93 - 0.97), which represents: Wood Beech, planned - 0.93, Wood Pine 0.95 , built-up areas showing $0.81-0.92$ values which are represents: Concrete - o.88, Brick, common - 0.85, Brick, glazed, rough - 0.85 , Plastics - 0.91 , bare soil (0.92 - 0.93), ground, dry ploughed - 0.90. 
Characterization of Surface Heat Fluxes over Heterogeneous Areas Using Landsat 8 Data for Urban Planning Studies Journal of Settlements and Spatial Planning, vol. 8, no. 1 (2017) 49-58
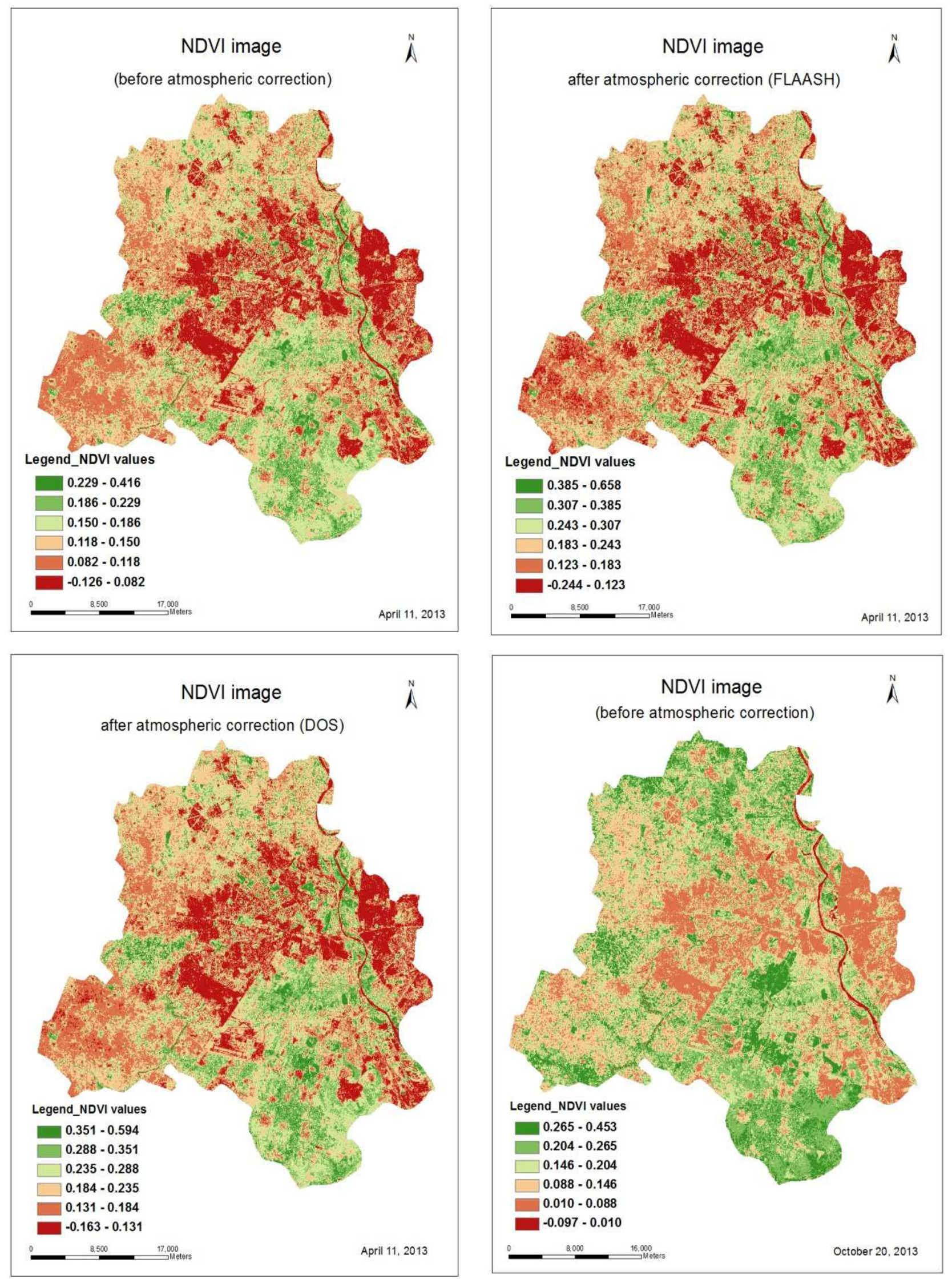
Tatygul URMAMBETOVA

Journal of Settlements and Spatial Planning, vol. 8, no. 1 (2017) 49-58
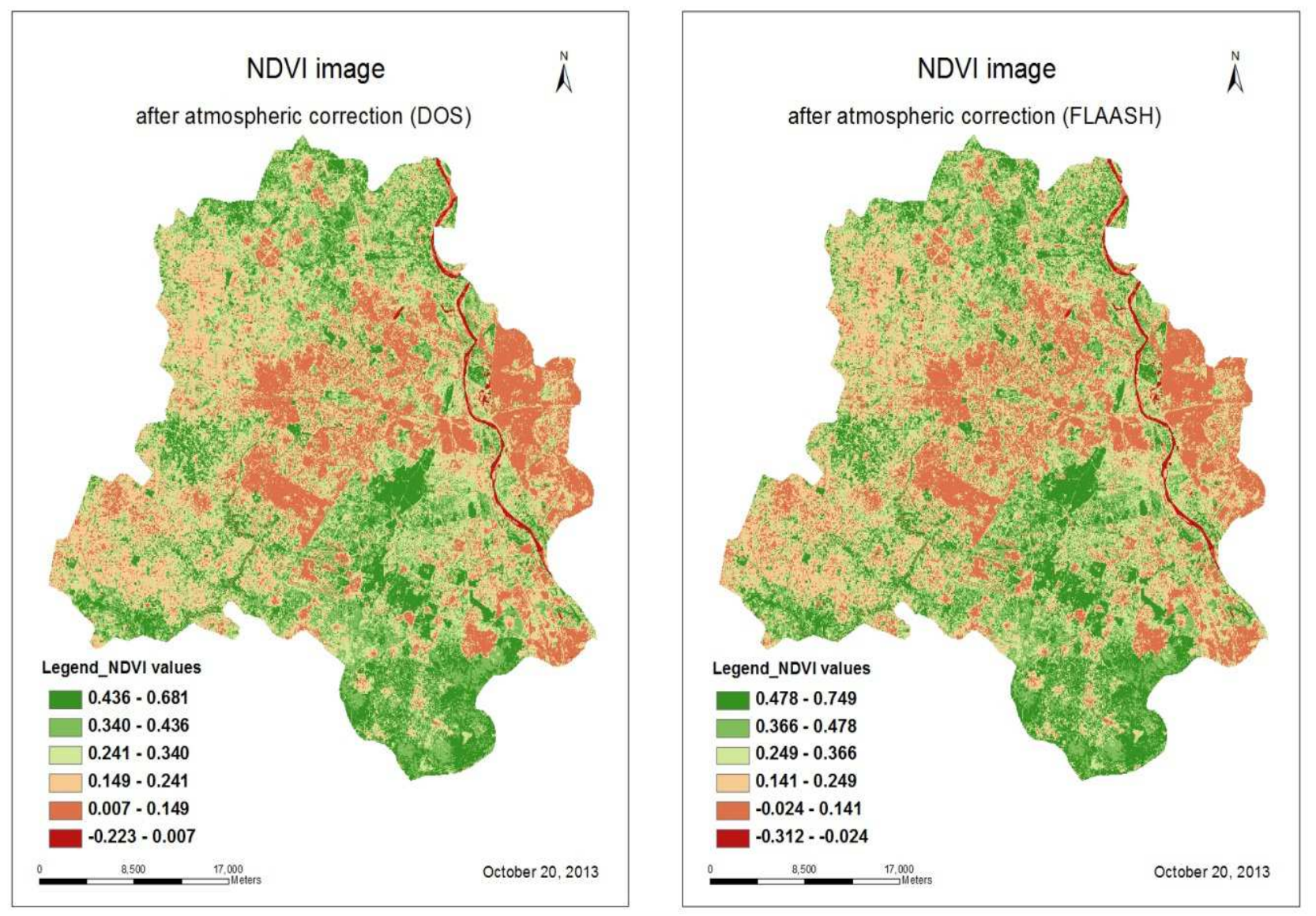

Fig. 4. Comparison of NDVI images before and after atmospheric corrections.

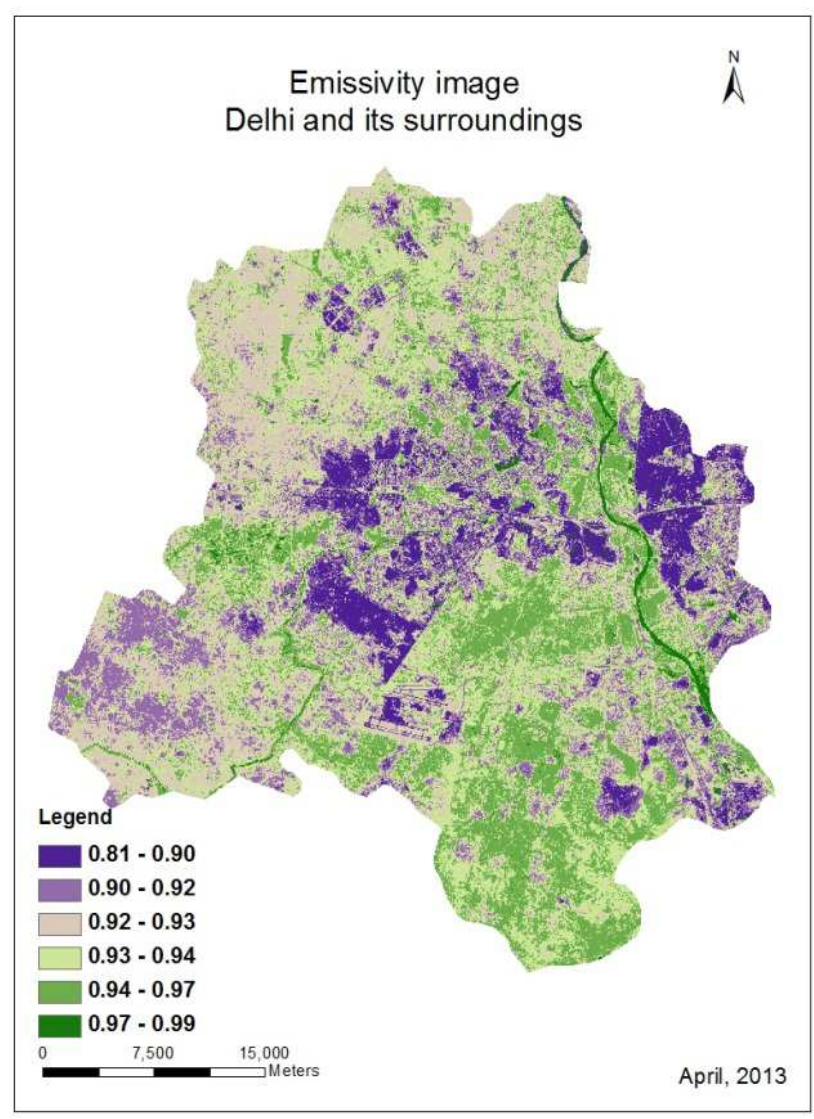

Fig. 5. Emissivity image of study area. 
Characterization of Surface Heat Fluxes over Heterogeneous Areas Using Landsat 8 Data for Urban Planning Studies Journal of Settlements and Spatial Planning, vol. 8, no. 1 (2017) 49-58
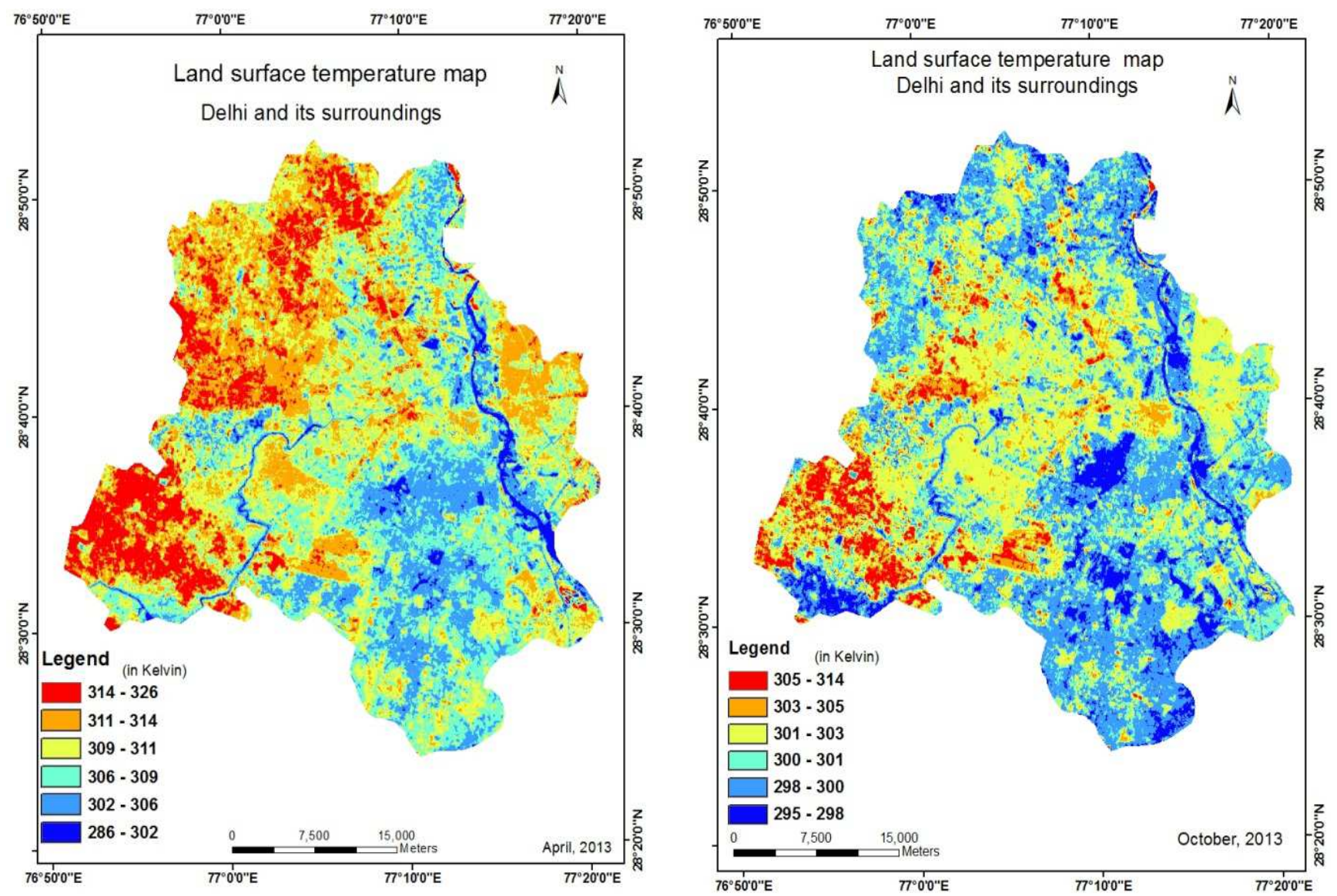

Fig. 6. LST map of study area.
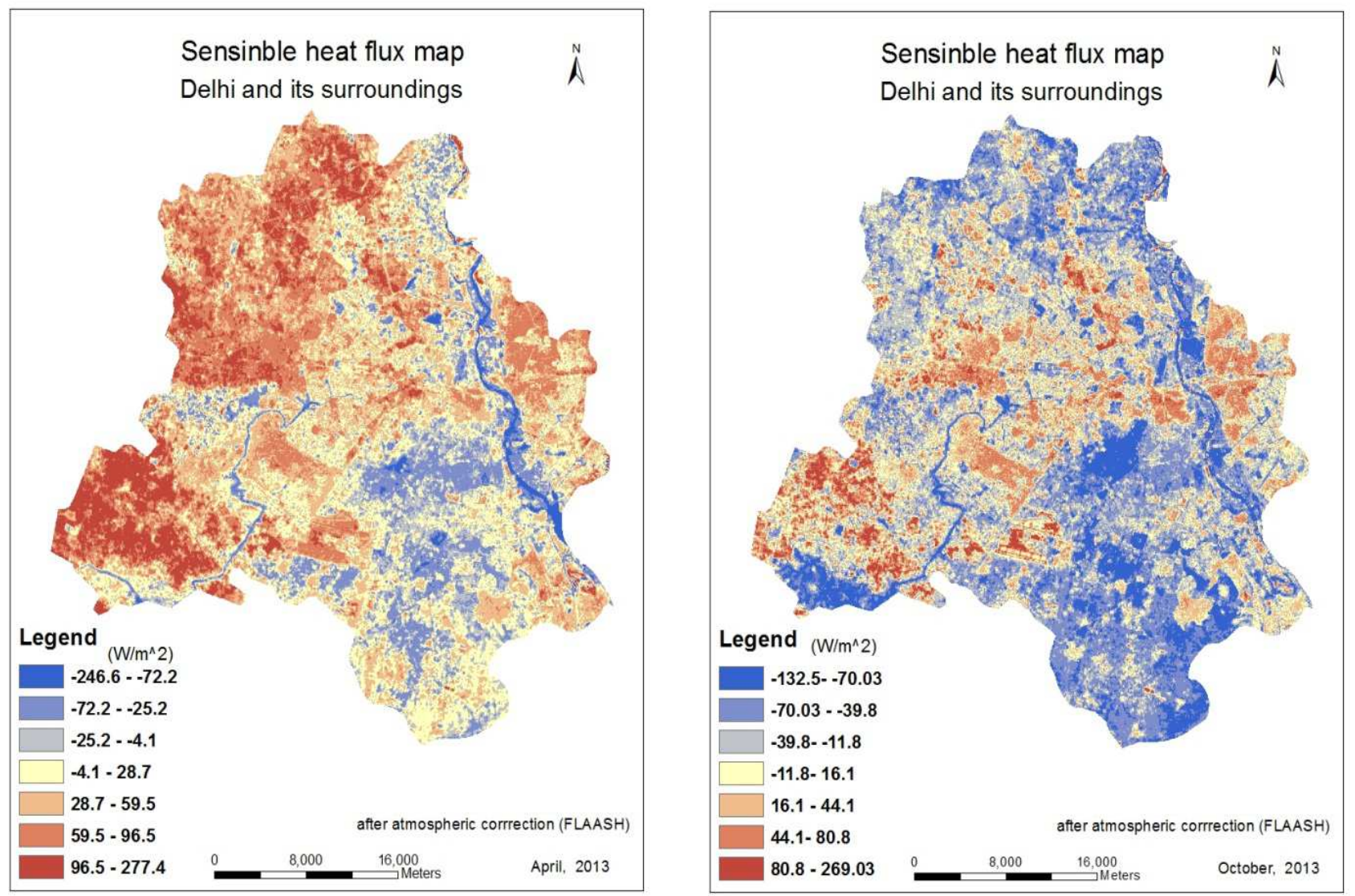

Fig. 7. SHF map of study area. 


\subsection{Analysis of emissivity}

Emissivity was estimated based on the NDVI values of the both images. Emissivity values observed were in the range between 0.81 and 0.99 .

\subsection{Land surface temperature and relation with normalized difference vegetation index}

In this study area the highest values of LST indicate the bare soil and high dense built-up areas, lower LST (except water bodies) is usually measured in areas with higher NDVI values (forest, agriculture/park). Figure 6 shows the LST map of study area.

\subsection{Analysis of sensible heat flux over various Land use/ Land cover}

Sensible heat flux (SHF) values for April, 2013 were found to vary between -252 and $229.3\left(\mathrm{~W} / \mathrm{m}^{2}\right)$, and for October, 2013 between -100.2 and $227.1 \mathrm{~W} / \mathrm{m}^{2}$ respectively. Higher values of SHF were found over the bare soil and lower values over water bodies/marshy areas. Figure 7 depicts the sensible heat flux image of the study area.

A comparison of the estimated values with and without using atmospheric correction was done to see the improvement in the estimated derived parameters.

Table 3 shows the details of improvement on individual parameters.

Table 3. LULC values after DOS and FLAASH atmospheric corrections

\begin{tabular}{|c|c|c|c|c|c|}
\hline & LULC classes & NDVI & LST & SHF & Emissivity \\
\hline \multirow{6}{*}{$\begin{array}{l}\text { After DOS } \\
\text { atmospheric } \\
\text { correction, April } \\
11,2013\end{array}$} & Water body & 0.026 & 298.544 & -106.192 & 0.99 \\
\hline & Forest & 0.4344 & 300.974 & -78.506 & 0.973 \\
\hline & $\begin{array}{l}\text { High dense built- } \\
\text { up }\end{array}$ & 0.094 & 312.902 & 66.922 & 0.8906 \\
\hline & $\begin{array}{l}\text { Low dense built- } \\
\text { up }\end{array}$ & 0.1052 & 310.512 & 39.11 & 09096 \\
\hline & Agriculture/Park & 0.3806 & 303.344 & -49.576 & 0.965 \\
\hline & Bare soil & 0.1288 & 316.914 & 116.3 & 0.9134 \\
\hline \multirow{7}{*}{$\begin{array}{l}\text { After DOS } \\
\text { atmospheric } \\
\text { correction, October } \\
20,2013\end{array}$} & Water body & -0.084 & 296.62 & -53.25 & 0.99 \\
\hline & Forest & 0.5648 & 297.102 & -51.17 & 0.9778 \\
\hline & $\begin{array}{l}\text { High dense built- } \\
\text { up }\end{array}$ & 0.046 & 301.76 & 32.754 & 0.8678 \\
\hline & Low dense built- & & & & \\
\hline & up & 0.104 & 301.194 & 29.104 & 0.9106 \\
\hline & Agriculture/Park & 0.4644 & 299.738 & -13.478 & 0.966 \\
\hline & Bare soil & 0.134 & 305.97 & 97.832 & 0.914 \\
\hline \multirow{6}{*}{$\begin{array}{l}\text { After FLAASH } \\
\text { atmospheric } \\
\text { correction, April } \\
11,2013\end{array}$} & Water body & 0.075 & 295.72 & -140.615 & 0.99 \\
\hline & Forest & 0.446 & 304.51 & -35.185 & 0.96 \\
\hline & $\begin{array}{l}\text { High dense built- } \\
\text { up }\end{array}$ & 0.056 & 313.31 & 72.22 & 0.87 \\
\hline & & 0.101 & 311.06 & 44.81 & 0.89 \\
\hline & Agriculture/Park & 0.39 & 304.23 & -37.37 & 0.95 \\
\hline & Bare soil & 0.108 & 318.74 & 139.13 & 0.9 \\
\hline \multirow{6}{*}{$\begin{array}{l}\text { After FLAASH } \\
\text { atmospheric } \\
\text { correction, October } \\
20,2013\end{array}$} & Water body & -0.14 & 295.85 & -100.94 & 0.99 \\
\hline & Forest & 0.59 & 296.99 & -75.25 & 0.98 \\
\hline & $\begin{array}{l}\text { High dense built- } \\
\text { up }\end{array}$ & 0.053 & 309.84 & 70.54 & 0.85 \\
\hline & $\begin{array}{l}\text { Low dense built- } \\
\text { up }\end{array}$ & 0.1183 & 306.99 & 45.32 & 0.9 \\
\hline & Agriculture/Park & 0.505 & 300.02 & -54.69 & 0.97 \\
\hline & Bare soil & 0.155 & 312.02 & 102.34 & 0.91 \\
\hline
\end{tabular}

\section{CONCLUSION}

Delhi and its surroundings are experiencing a rapid urbanization. With urbanization most of the land surface is covered with concrete, asphalt and other such impervious materials. The urban areas experiencing more heat than the surrounding rural areas, mainly due to lack of vegetative cover. Remotely sensed image has 
the capability of estimation Emissivity, LST and SHF parameters. In this research work Landsat 8 images of Delhi and its surroundings were downloaded from USGS earth explorer web site. After pre-processing the data was noted that after applying Model-Based atmospheric correction (FLAASH) NDVI values has been improved. Surface temperature is retrieved to understand the variation of temperature from Vegetated areas to Low dense built-up and High dense built-up. Emissivity values of land surface features are influence for characterization of LST and SHF. From the LST maps it is clearly understood that surface temperature is high in High dense built-up areas comparatively to Low dense built-up areas. It was observed that maximum land surface temperature in bare soil areas and minimum LST in areas where it covered by vegetation and water bodies. LST values were used in deriving Sensible heat flux values over land use land cover classes of study area. The correlation study shows that the LST is negatively correlated with NDVI. After learning the relationship of derived parameter it was observed that LST and SHF values are directly proportional. In addition, to see the relationship of NDVI and LST values in temporal resolution suggested using multi temporal data.

For better planning and management of urban areas and their surrounding rural lands, we suggest using remotely sensed data and variety of climate factors. This information enhances our understanding of urban environment and can be further used to improve environment quality.

For the urban planning strategies, improvement of urban environment and heat island reduction, the relationship between urban surface temperature and land use/land cover classes helps us find out the best solution.

\section{ACKNOWLEDGEMENTS}

First and foremost, I would like to extend my deepest gratitude to my supervisors Dr. Yogesh Kant and Mrs. Shefali Agrawal for their support, guidance, suggestions and for sharing their knowledge with me during my study at Indian Institute of Remote Sensing (Dehradun, India). I am highly gratitude to Indian Government and United Nations for granting me the scholarship under CSSTEAP (Centre for Space Science and Technology Education in Asia and the Pacific) program.

\section{REFERENCES}

[1] Srivastava, P. K., Majumdar, T. J., Bhattacharya, K. Amit (2010), Study of land surface temperature and spectral emissivity using multisensor satellite data. J. Earth Syst. Sci. 119, No. 1, pp. 67-74.
[2] Alipour, T., Sarajianb, M. R., Esmaeily, A. (2010), Land surface temperature estimation from thermal band of Landsat sensor, case study: Alashtar city. The International Archives of the Photogrammetry, Remote Sensing and Spatial Information Sciences, Vol. XXXVIII-4/C7; Available at: https://pdfs.semanticscholar.org/9026/5c96obe2bdda 552d5cdob394bc802cb73263.pdf/.Last accessed May 30, 2017.

[3] Mallick Javed, Kant Yogesh, Bharath, B. D. (2008), Estimation of land surface temperature over Delhi using Landsat-7 ETM+. J. Ind. Geophys. Union Vol.12, No.3, pp.131-140.

[4] Sundara Kumar, K., Udaya Bhaskar, P., Padmakumari, K. (2012), Estimation of land surface temperature to study urban heat island effect using Landsat ETM + image. International Journal of Engineering Science and Technology (IJEST) Vol. 4, pp. 771-778.

[5] Weng Qihao, Lu Dengsheng, Schubring Jacquelyn (2004), Estimation of land surface temperature-vegetation abundance relationship for urban heat island studies. Remote Sensing of Environment 89, pp. 467-483.

[6] Yuan Fei, Bauer E. Marvin (2007), Comparison of impervious surface area and normalized difference vegetation index as indicators of surface urban heat island effects in Landsat imagery. Remote Sensing of Environment 106, pp. 375-386.

[7] Mohan Manju, Pathan K. Subhan, Narendrareddy Kolli, Kandya Anurag, Pandey Sucheta, (2011), Dynamics of Urbanization and Its Impact on Land-Use/Land-Cover: A Case Study of Megacity Delhi, Journal of Environmental Protection, No 2, pp. 1274-1283.

[8] Tyagi Priti, Bhosle Udhav (2011), Atmospheric Correction of Remotely Sensed Images in Spatial and Transform Domain. International Journal of Image Processing (IJIP), Volume (5) : Issue (5), pp. 564-579.

[9] Jackson, R. D., Huete, A. R. (1991), Interpreting vegetation indices. Preventive Veterinary Medicine, 11, pp. 185-200;

[10] Jensen, R. J. (2007), Remote Sensing of the Environment: An Earth Resource Perspective. Second Edition, published by Pearson Education Inc, India

[11] Prakash Anupma (2000), Thermal remote sensing: concepts, issues and applications. International Archives of Photogrammetry and Remote Sensing. Vol. XXXIII, Part B1;

[12] Gao Caixia, Tang Bo-Hui, Wu Hua, Jiang Xiaoguang, Li Zhao-Liang (2013), A generalized split-window algorithm for land surface temperature estimation from MSG-2/SEVIRI data, International Journal of Remote Sensing, Vol. 34, No. 12, 4182-4199. [13] Mao, K., Qin, Z., Shi, J., Gong, P. (2005), A practical split window algorithm for retrieving land surface temperature from MODIS data. International Journal of Remote Sensing, 26:15, pp.3181-3204; 
[14] Yu Yunyue, Privette L.Jeffrey, Pinheiro C. Ana (2008), Evaluation of split-window land surface temperature algorithms for generating climate data records. IEEE Transactions on geoscience and remote sensing, VOL. 46, NO. 1, pp. 179-208;

[15] Barsi, J. A., Schott, J. R., Palluconi, F. D. D., Helder, L., Hook, S. J., Markham, B. L., Chander, G., O'Donnell, E. M. (2003), Landsat TM and ETM+ thermal band calibration. Can. J. Remote Sensing, Vol. 29, No. 2, pp. 141-153.
[16] Sobrino, A. Jose, Jimenez-Munoz, C. Juan, Paolinib, L. (2004), Land surface temperature retrieval from LANDSAT TM 5. Remote Sensing of Environment 90, pp. 434 - 440; Available at:http://www.uv.es/ucg/articulos/2005/Publications_ 2004_10.pdf/. Last accessed May 30, 2017.

[17] Liu S., Mao, D., Lu, L. (2006), Measurement and estimation of the aerodynamic resistance. Hydrology and Earth System Sciences Discussion, 3, pp. 681-705. 